\title{
EMOÇÕES E SOCIEDADE: UM PASSEIO NA OBRA DE NORBERT ELIAS
}

\author{
Emotions and society: a walk in the \\ work of Norbert Elias \\ Mauro Guilherme Pinheiro Koury*
}

\begin{abstract}
RESUMO
Este ensaio é uma introdução ao modo de pensar e fazer sociológico e aos processos de construções novas realizadas pela sociologia de Norbert Elias. Busca compreender a importância da obra de Norbert Elias para a análise social, cultural e histórica, tendo como lugar principal de fala a sociologia e como recorte de olhar, específico, a economia emocional por ele proposta e sua contribuição à sociologia das emoções. Em um primeiro andamento, o ensaio faz uma pequena abertura discursiva às diversas sociologias contidas na obra de Elias. Em seguida, procura realizar um sobrevoo nas relações tensas e de equilíbrio frágil entre indivíduo e sociedade, pairando sobre o processo de adequação e consolidação de uma nova sensibilidade ocidental, por meio da internalização dos sentimentos e, em particular, da vergonha como motriz da ação individual no cultural e no societal. No momento final discute as noções de habitus e de rede humana configuracional.
\end{abstract}

Palavras-chave: Norbert Elias; economia e cultura emocional; habitus; redes humanas.

\begin{abstract}
This paper is an introduction to the way of thinking and doing sociological processes and new constructions undertaken by the sociology of Norbert Elias. It seeks to understand the importance of the work of Norbert Elias to analyze social, cultural and historical, whose principal place of talking sociology, and cut to look like, specifically, the emo-

"Doutor em Sociologia e Professor dos Programas de Pós-Graduação em Antropologia (PPGA) e de Direitos Humanos (PPGDH) da Universidade Federal da Paraíba. Coordenador do GREM - Grupo de Pesquisa em Antropologia e Sociologia das Emoções da mesma universidade.
\end{abstract}


tional economy proposed by him and his contribution to the sociology of emotions. In a first movement, the essay makes a small opening to the various discursive sociologies contained in the work of Elias. It then attempts to perform a flyover in relations strained and fragile balance between individual and society, hovering over the process of adjustment and consolidation of a new Western sensibility through internalization of feelings and in particular shame as the motives of individual action in cultural and societal. In the final moment eliasiana discusses the notions of habitus and configuracional human network.

Keywords: Norbert Elias; economy and culture emotional; habitus; human networks.

\section{As diversas sociologias de Elias e as emoções}

A obra eliasiana foca, principalmente, a relação entre poder, comportamento, emoções e conhecimento nos processos sociais e históricos. Devido a circunstâncias históricas ${ }^{1}$ - como o exílio, o estado de pobreza, a precariedade de uma estabilidade no trabalho até 1954, o sofrimento íntimo pelo sentimento de culpa pela morte da mãe em um campo de concentração e, sobretudo, problemas ligados ao processo de tradução de suas obras, principalmente na sua versão para o inglês -, Elias permaneceu durante um longo período de sua vida, mesmo depois de estabilizado como professor na Universidade de Leicester, como um autor marginal, ou, nas palavras de Kilminster (1995, p. VIII), na periferia da sociologia instituída e, assim,

1 Norbert Elias nasceu em 22 de junho de 1897, filho de uma família judia, em Breslau

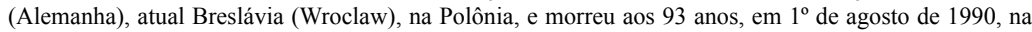
cidade de Amsterdã, capital da Holanda, lugar que escolheu para viver seus últimos anos de vida. Estudou medicina e filosofia em um momento em que a psicanálise freudiana estava em pleno desenvolvimento e formou-se em Sociologia, em um período também em que a sociologia alemã era dominada pelo pensamento de Max Weber. De família judia, teve de fugir da Alemanha nazista um pouco depois de sua defesa de doutorado em Filosofia, exilando-se em 1933 na França, antes de se estabelecer na Inglaterra, em 1935, onde passa grande parte de seu exílio. Em Londres, Elias viveu de forma precária, antes de obter em 1954 um posto de professor na Universidade de Leicester. Sobre o sofrimento psíquico e emotivo de Elias durante todo o período de exílio, Dunning e Mennell (1997) e Kilminster (1995) informam que ele nunca se recuperou do sentimento de culpa que o acompanhou durante toda a sua vida, por ter conseguido escapar do nazismo alemão, sem, contudo, conseguir tirar sua mãe da Alemanha, que acabou morta nas câmaras de gás de Auzuitch. 
distanciado dela. Norbert Elias e sua obra vieram a ser descobertos por uma nova geração de teóricos das ciências sociais no final dos anos de 1970, vindo a se tornar um dos mais influentes sociólogos do século XX e um cientista social cada vez mais influente no século XXI.

Sua influência atual pode ser atribuída, entre outros aspectos, às concepções do social como composto por grandes redes sociais e à economia emocional, que envolve as relações complexas entre indivíduos interdependentes. Estas noções encontraram uso e aplicação nas sociedades ocidentais contemporâneas, onde a presença da ação individual não pode ser negligenciada, ao mesmo tempo em que a ênfase focada primordialmente no papel da estrutura social sobre o indivíduo, até então em vigor, decai e começa a ser criticada; isto, é bom frisar, desde os anos de 1968, onde os gritos rebeldes giravam em torno de uma maior visibilidade e liberdade para o indivíduo nos planos cultural e social.

No conjunto da obra eliasiana, se destacam como um dos seus livros mais importantes e influentes os dois volumes de $O$ processo civilizador (ELIAS, 1990; 1993). O processo civilizador foi originalmente publicado em 1939, em dois volumes, por uma editora suíça especializada em publicação de autores judeus, e, em um só volume, na primeira edição inglesa de 1944, que não obteve boa aceitação, tendo passado em branco pela comunidade e pela crítica acadêmica da época, que, completamente, o ignorou.

O processo civilizador teve uma segunda edição suíça em 1969. Nesse momento, o livro começou a ter uma pequena expressão, ainda que assustada, junto à academia; e, logo após esse primeiro impacto, foi literalmente ignorado até sua redescoberta, em 1978, quando de sua segunda edição inglesa. A publicação desta segunda edição causou uma série de sentimentos, discussões e debates, que variaram desde acusações e rejeições a grandes processos de aceitabilidade como novidade teórico-metodológica no mundo das ciências sociais.

O primeiro volume de O processo civilizador (ELIAS, 1990) possui o subtítulo Uma história dos costumes e discute os acontecimentos históricos do habitus europeu, isto é, a estrutura psíquica individual moldada pelas atitudes sociais. O segundo volume de O processo civilizador (ELIAS, 1993), com o subtítulo Formação do estado e civilização, aborda, por sua vez, as causas destes processos e os reconhece nas, cada vez mais, centralizadas e diferenciadas interconexões na cultura e na sociedade. 
Neles, Elias procurou demonstrar como os padrões europeus pós-medievais de violência, comportamento sexual, funções corporais, etiqueta à mesa e formas de discurso foram gradualmente transformados pelo crescente domínio da vergonha e do nojo, atuando para fora de um núcleo de etiqueta cortês. Elias descreve, neste volume, a partir da análise de manuais de etiqueta e de códigos e tratados de conduta e comportamento, como os conceitos de cortesia, civilidade e civilização vão se sucedendo na Europa, de maneira a demonstrar, em detalhes, como o cotidiano dos indivíduos ${ }^{2}$ está vinculado a padrões de experiência e vivência da vergonha e seus corolários, como o embaraço, a humilhação, o ressentimento, a baixa autoestima, a falta de autoconfiança, entre outros, bem como às noções estreitamente correlacionadas ao ato de envergonhar-se, como o sentimento de honra, o sentimento de orgulho e o autorrespeito em uma ordem moral que estrutura as emoções individuais conforme a diferenciação das funções sociais em uma sociabilidade dada (ELIAS, 1990) ${ }^{3}$.

Elias argumenta que o processo civilizador ocidental se distingue de outros processos civilizacionais pela monopolização da violência física e fiscal em regiões pacificadas e submetidas a centros de poder em equilíbrio relativamente estável, o que permite a conformação e estabilização de um habitus pautado na gerência e no refinamento das emoções como estratégia de hierarquização e distinção social, por meio da internalização dos sentimentos e, em particular, da vergonha como motriz da ação individual no cultural e no societal.

A vergonha internalizada, a partir do próprio indivíduo, estampa uma eficaz agência de autocontrole e de autolimitação, em formas conscientes e inconscientes, de modo ambíguo e ambivalente, para o indivíduo. Indivíduo social cuja estrutura mental sofre um alargamento e uma fragmentação e distinção consideráveis, elevando, em contrapartida, o custo e o tempo para uma socialização bem-sucedida. A vergonha passa a ser vivida como uma tensão, como uma espécie de agitação e desordem no interior da própria personalidade individual, que se debate conflitualmente nos limites impostos pela rede de interdependências na qual se insere.

2 Isto é, gestos, expressões faciais, postura, vestuário, disciplina para o trabalho, comportamento à mesa, higiene corporal e outros.

3 Elementos que formam o centro básico e o núcleo compreensivo de uma cultura emocional no social, de importante alcance teórico-metodológico na sociologia das emoções. 
Na sua sociologia processual e da civilização, essas transformações graduais se dão pela noção de história como tempo longo. Nela e por meio dela a noção de tempo ganha o significado de uma síntese social que se apresenta como consciência da duração, da mudança e da referência retrospectiva e prospectiva de projetos individuais e coletivos. Para Elias (1998, p. 63 grifos no original), "os conceitos de passado, presente e futuro, expressam a relação que se estabelece entre uma série de mudanças e a experiência que uma pessoa (ou um grupo) tem dela". Seguindo esta linha de raciocínio, assim, os significados de passado, futuro e presente dependem das gerações vivas em cada momento socio-histórico singular e, como as gerações estão sempre interconectadas, era após era, os sentidos conceituais de longa duração não param de evoluir.

Nesse aspecto informa, observando e compreendendo o processo vivido para a modernidade ocidental, que a prudência e o equilíbrio das emoções consideradas espontâneas, o controle dos sentimentos e o alargamento do espaço intelectual e reflexivo para além do presente vivido arrastam consigo e alteram, a cada momento da evocação, os sentidos impressos ao passado e ao futuro, ao costume e à rotina de interligar "os fatos em cadeias de causa e efeito". Processos que fazem parte e são todos estes considerados como "distintos aspectos de uma mesma modificação e variação das condutas, que ocorrem necessariamente com [...] a extensão das cadeias da ação e interdependência social” (ELIAS, 1993, p. 198).

Ocorre, no seu desenvolvimento, assim, no interior da perspectiva eliasiana, como que uma mudança civilizadora do comportamento. Por meio dessa síntese social Elias demonstra, passo a passo, o processo por onde o autocontrole começa a ser exigido, cada vez mais, por uma rede multíplice de conexões sociais desenvolvidas por uma autopercepção psicológica ${ }^{4}$, mas percebida por meio de um elaborado e mais complexo conceito: o de habitus, que veremos com mais vagar adiante. A obra de Elias, deste modo, entre outros aspectos, pode ser compreendida como uma precursora de uma sociologia das emoções (SCHEFF, 2001) ou é portadora e promissora, como nos indicam Heinich (2001) e Mennell (1998), de uma sociologia dos afetos. Sociologia das emoções ou dos afetos que só pode ser pensada, no seu desenrolar metodológico, no interior de uma sociologia da história, do

4 Noção em Elias influenciada e próxima, mas com consequências práticas bastante dessemelhantes, do conceito freudiano de superego. 
tempo longo, processual e de uma sociologia das figurações, que dá sentidos às redes humanas como um jogo e um espaço de interações continuadas.

Elias aborda em sua análise processual e da civilização, em seu $O$ processo civilizador, o desenvolvimento das novas maneiras de gerenciamento das funções corporais e emocionais dos e pelos indivíduos em um contexto histórico e social ocidental, e compreende tal processo como a moldagem de uma nova sociabilidade e sensibilidade ${ }^{5}$ no Ocidente, que funda a modernidade alemã e europeia e se expande pelo mundo afora dominado pela ou sob a autoridade da ética e dos modos e estilos de vida ocidentais.

Para ele, a observação e a análise do surgimento e da insurgência desta nova sensibilidade se fazem mediante a compreensão da ampliação e da extensão dos sentimentos de vergonha e suas variantes: o embaraço, a aversão, a repugnância e o nojo. Estes, por sua vez, são aprendidos por meio de um processo de longa duração, civilizador, onde formas sociais características, nominadas por ele por meio da noção de sociogênese, e uma também específica economia psíquica das emoções e dos afetos, por ele conceituada de psicogênese, se consolidam. A relação tensa entre a sociogênese e a psicogênese em sua montagem de uma figuração em equilíbrio precário, assim, permitem a Elias uma formulação teórico-metodológica por meio da qual a história e a narrativa de uma sociedade se refletem em uma história e em uma narração interna de cada indivíduo.

O habitus, este conceito central na obra de Elias, resulta, então, de uma dinâmica configuracional de interdependência e equilíbrio de tensões entre os indivíduos e as redes social e cultural e entre os processos de distinção e hierarquia desenvolvidos em uma sociabilidade dada. No seu conhecido trabalho empírico sobre uma comunidade de trabalhadores industriais na Inglaterra dos anos de 1940, Elias (2000) discute as noções de habitus e de hierarquização entre os que ele denominou de estabelecidos e outsiders, estes últimos denominados como aqueles que vivem ou são colocados às margens do sistema. Analisa as barreiras, os obstáculos emocionais e as fronteiras de sensibilidade e reserva que se erigem e se organizam nesta comunidade e, concomitantemente, na estrutura mental dos indivíduos relacionais nela e a ela dispostos e expostos.

5 Para uma análise da moldagem de uma nova sensibilidade no Brasil urbano, ver Koury (1996; 2003). 
Modula, aqui, a noção de discrição já iniciada nos dois volumes de O processo civilizador como resultante da privatização da subjetividade ${ }^{6}$, bem como das noções de orgulho e vergonha, consideradas como emoções fundamentais na microfundamentação do social (SCHEFF, 1990). Nesta análise das relações de poder em uma pequena comunidade, Elias utiliza o conceito de habitus para fugir da dicotomização entre indivíduo e sociedade, procedimento bem-sucedido quando demonstra que as emoções individuais, e a própria cultura emotiva, derivam de processos coletivos de incorporação de formas de ser e estar no mundo a partir de processos tensos, conflituais de negociação e disputa entre estabelecidos e os considerados de fora da comunidade e que contagiam com seus modos e estilos de vida não condizentes com o costume e a moral local.

Para Elias, em suma, o indivíduo se apresenta como uma síntese complexa de um contexto sócio-histórico singular, dotado de uma configuração exterior e de uma interioridade. A figuração do autocontrole individual está associada, assim, à forma social de distribuição de bens materiais e simbólicos, do controle da violência física e de divisão do trabalho que exigem do indivíduo uma busca permanente para obtenção de saberes específicos. A sociologia configuracional de Elias, nesse sentido, pode ser vista como um espaço de interações e de redes intercomunicantes, onde as correlações são sempre relacionais e o indivíduo existe, enquanto tal, apenas quando compondo uma rede de interdependências, em um sistema de interações sempre tenso e conflitual, por onde se realiza sua identidade individual e social e se organiza sua vida emocional.

A obra, como já anunciado acima, e de acordo com Dunning e Mennell (1997), no prefácio brasileiro de Os alemães, teve difícil aceitação na Grã-Bretanha, na sua primeira edição inglesa, continuando esta dificuldade também logo após a segunda edição em 1978, tanto na Grã-Bretanha quanto nos EUA, por mal-entendidos ligados, segundo os autores citados, à questão de tradução do alemão para o inglês.

Neste momento, cabe fazer aqui uma breve digressão: Thomas Scheff (2003, p. 241-242), sociólogo americano que trabalha com a sociologia das emoções, em um artigo sobre o impacto causado pel' O processo

6 Seria estimulante, aqui, uma análise comparativa com o mesmo processo em Simmel, cujo conceito de discrição é a tônica para se pensar a privatização do indivíduo na sociabilidade moderna ocidental, que será feita em outro momento, já que fugiria em termos do objetivo deste ensaio. 
civilizador de Elias, afirma que a grande dificuldade na aceitação da obra nos países de língua inglesa, principalmente na Grã-Bratanha e nos Estados Unidos, foi devido à dificuldade de tradução, principalmente, do conceito de vergonha eliasiano, como vimos acima, noção fundamental para entender o processo de autocontrole no interior do processo civilizador analisado.

Informa Scheff que, diferente do alemão, que possui dois termos para expressar vergonha, o Schande (vergonha de sentir vergonha) e scham (vergonha cotidiana), em inglês só existe uma expressão para a palavra vergonha (shame), que é próxima do Schande alemão. O termo vergonha, ao ser traduzido pela sua expressão literal inglesa e lido nessa direção, causou uma certa repugnância, de acordo com Thomas Scheff, no texto acima citado, ao conceito eliasiano, já que a aspereza da palavra em inglês bloqueava toda área de pessoalidade do debate e insinuava apenas a vergonha de sentir vergonha, que é um termo com forte tensão e sentido de ofensa, tanto social quanto no plano individual.

É importante salientar, ainda, que outro impacto negativo também circunscreveu as primeiras edições d'O processo civilizador. Assim, quando a obra de Elias começou a ser acolhida, sua análise do processo social foi mal compreendida, não só pelo aspecto do autocontrole, tendo a vergonha como um dos principais conceitos, mas também porque foi vista como uma nova teoria evolucionista da sociedade, como uma espécie de darwinismo social. Mais tarde, contudo, esta primeira compreensão começou a ser abandonada - embora se apresente argumentos nessa direção até hoje - e a sua obra começa a ser entendida a partir de uma outra chave compreensiva, ou seja, como uma teoria voltada para a análise dos processos sociais.

Os estudiosos da obra de Norbert Elias, como Mennell (1998), Heinich (2001) e Scheff $(2001 ; 2002)$, por exemplo, acreditam que ele desenvolveu uma sociologia complexa para se pensar o social contemporâneo e acreditam que sua obra pode ser pensada através de três grandes caminhos teórico-metodológicos: um caminho para uma Sociologia Processual, outro para uma Sociologia Figuracional e um terceiro para uma Sociologia dos Afetos e das Emoções. Esses três caminhos, contudo, se cruzam a todo momento e podem ser pensados como sendo apenas uma divisão metodológica e teórica abstrata para melhor pensar a construção e a lógica interna da obra eliasiana.

A Sociologia Figuracional eliasiana, assim, por exemplo, examina a origem e a constituição de configurações sociais como resultados não 
premeditados da interação social. Nela, ou por meio dela, a sociedade e sua cultura são vistas como uma formação oriunda do conjunto dos seres humanos, que dela fazem parte, em uma pluralidade não planejada e, muito menos, pretendida por nenhum indivíduo em particular ou pelo conjunto dos indivíduos a ela ou nela situados.

A análise sociológica para Elias, nessa trajetória, é nada mais nada menos do que um grande esforço teórico na e de representação da sociedade como teias ou redes de indivíduos interdependentes. Teias e redes por ele chamadas de figurações, por intermédio das quais e por onde sentimentos, decisões, ações, atitudes e relações mudam em respostas a processos e desenvolvimentos sociais.

Estas figurações, como teias ou redes, em seus movimentos contínuos, estão sujeitas tanto a processos civilizadores quanto a processos descivilizadores ${ }^{7}$, ambos podendo ocorrer simultaneamente em uma determinada sociedade e cultura e não apenas em diferentes sociedades e culturas, ou em sociedades e culturas específicas em diferentes pontos do tempo ${ }^{8}$.

A análise sociológica eliasiana busca, nessa direção, resolver uma questão central das ciências sociais, que é a oposição entre indivíduo e sociedade, por meio do que ele vai nominar de sociedade dos indivíduos - e vai explorar conceitualmente, e desenvolver em uma direção mais diretamente metodológica, em uma coleção de ensaios que compõem o livro do mesmo nome, Sociedade dos indivíduos (ELIAS, 1994). Para Elias, assim, essa oposição é resolvida ao se considerar o âmbito social como composto pelas leis autônomas das relações entre as pessoas individualmente consideradas. Para ele, portanto, o indivíduo sempre existe na relação com os outros, e essa relação possui uma estrutura particular, que é específica da sociedade em que os indivíduos vivem.

Essa relação singular, em Elias, sempre satisfaz um processo de individualização, que impele cada indivíduo, por meio da estrutura social, que ele chama de Rede Humana, a um alto grau de controle e transformação

7 Para uma definição e análise sobre os processos descivilizadores ver, principalmente, a grande obra eliasiana Os alemães (1997).

8 Cabe, nesse momento, mais uma pequena digressão explicativa desse movimento e sua implicação para a análise sociológica e para a análise das ciências sociais e históricas: para Elias, sempre existe um grau de indeterminação nos processos sociais, acompanhando, deste modo, a análise weberiana e simmeliana de indeterminação. Ao pensar a disciplina sociológica como disciplina científica, ele informa que, embora toda compreensão possibilite predições de uma ou outra espécie; qualquer tentativa nessa direção pode ser desastrosa e não passar de apenas profetizações sobre o futuro. 
dos seus instintos. Daqui dá para ver e inferir as constantes intersecções entre a sua análise no interior de uma Sociologia dos Afetos e das Emoções e seus cruzamentos e entrecruzamentos com os veios analíticos de suas Sociologias Figuracional e Processual.

O processo de individualização, assim, nada mais é do que um tecer e destecer ininterrupto das ligações dos seres humanos com outros seres humanos. É, nesse sentido, por meio dessa construção contínua do que ele denomina de rede humana ${ }^{9}$, e através de relações sociais estabelecidas no seu interior, que a teoria eliasiana tenta resolver a questão da relação indivíduo e sociedade. Os seres humanos, juntos, compõem um contínuo sócio-histórico, de onde cada um deles e por onde cada pessoa cresce e se desenvolve como participante e coparticipante desse contínuo, a partir de um determinado ponto desse processo ou continuum sócio-histórico singular.

Nessa ideia processual, está implícito que o indivíduo nasce, cresce e se desenvolve a partir de um momento específico desse contínuo, que molda e compromete o indivíduo dentro das Redes ou Teias de Sentidos de uma configuração social específica e lhe confere todo o alcance de sua vida. O que significa e demonstra, em outras palavras, a dependência do indivíduo em relação aos outros e a dependência dos outros a ele. Ou melhor, e ainda, às funções dos outros para com ele (indivíduo) e as funções dele para com os outros.

Esse continuum de seres humanos interdependentes, para Elias, deste modo, é o objeto de estudo principal da Sociologia, seja ela Figuracional, Processual, mas também a dos Afetos e das Emoções. Já que todas se complementam e constroem a singularidade do objeto e da análise sociológica, e por que não, das ciências sociais e históricas. Seguindo nesse raciocínio e de acordo com a formulação eliasiana, se chega à conclusão plausível de que a Rede Humana ou Sociedade produz não apenas o semelhante e o típico, mas também o individual. Deste modo, uma pessoa qualquer só pode dizer eu se e porque pode dizer nós. Nesse momento, o seu conceito de habitus pode ajudar bastante nesta reflexão.

9 Em Elias, é bom frisar e é sempre bom pensar também que o contínuo não pode ser pensado sem possibilidade de descontinuidade. 


\section{O conceito de habitus em Elias}

Antes de iniciar a discussão da noção de habitus em Elias, é necessário mais uma pequena digressão: o termo habitus usado por Elias no livro O processo civilizador, de 1939, seria utilizado por ele, de forma contundente, mais tarde, quase 40 anos depois, em Os alemães (ELIAS, 1997), obra considerada por alguns autores como seminal e para outros a sua segunda mais importante desde $O$ processo civilizador, e nos livros $A$ sociedade de corte (ELIAS, 2001), Os estabelecidos e os outsiders (ELIAS, 2000), A sociedade dos indivíduos (ELIAS, 1994), entre outros.

De acordo com Dunning e Mennell (1997, p. 9), o conceito de habitus, apesar de popularizado por Pierre Bourdieu, foi usado de forma contundente por Elias em seu seminal O processo civilizador, de 1939; Nathalie Heinich (2001) corrobora o argumento de Dunning e Mennell e conta que Pierre Bourdieu teve acesso a um dos exemplares de $O$ processo civilizador, na sua edição de 1939, de um Elias ainda às margens da sociologia instituída e anônimo para o grande público acadêmico, dele retirando o conceito de habitus, sem o citar, e o popularizando, fazendo dele um dos conceitos-chave de sua sociologia.

No livro sobre Trabalho e trabalhadores na Argélia, de 1963 (BOURDIEU, 1963), utiliza pela primeira vez o conceito de habitus - que, nesse primeiro momento de uso, corresponde a uma espécie de matriz, determinada pela posição social do indivíduo: o que permite a quem o veste pensar, ver e agir nas mais variadas situações. O conceito de habitus na sua utilização posterior, em Bourdieu, sobretudo a partir do livro $A$ distinção, de 1979 (BOURDIEU, 2011), traduz estilos de vida, julgamentos políticos, morais e estéticos e é, também, um meio de ação que permite criar ou desenvolver estratégias individuais e coletivas.

O conceito bourdiesiano de habitus, assim, de acordo com Heinich, seria uma apropriação da noção eliasiana de habitus $^{10}$. Para Bourdieu, tanto quanto para Elias, a noção de habitus evidencia a dependência dos indivíduos em relação aos comportamentos, ao mesmo tempo apreendidos

10 Como um autor desconhecido do grande público e mesmo no interior da academia na época, Bourdieu não se preocupou em citá-lo, apropriando-se do conceito e dando ao mesmo uma roupagem pessoal. 
e próprios do grupo a que o indivíduo pertence. Porém, seguindo Heinich (2001, p. 131), diferente da proposta eliasiana circunscrita em seu conceito e aplicação de habitus, a noção de habitus em Bourdieu não está relacionada com a livre-escolha dos indivíduos.

O conceito de habitus para Elias, portanto, vai além e significa a configuração social dos indivíduos, uma espécie de um saber social incorporado, ou uma segunda natureza do indivíduo em sociedade. Segundo Dunning e Mennell (1997), o conceito foi usado por Elias para, em grande parte, superar os problemas trazidos pela antiga noção de caráter nacional, muito usada na sociologia e na antropologia, principalmente americana, do início do século XX.

Para Elias, a identidade eu-nós é parte integrante do habitus social de uma pessoa e, como tal, se encontra aberto à individualização. A noção de habitus em Elias, assim, é uma construção conceitual que utiliza a figura de uma espécie de balança eu-nós como instrumento de observação. Balança eu-nós essa que indica sempre um equilíbrio tenso e frágil na relação entre indivíduo (eu) e sociedade (nós), fortalecendo o seu entendimento da rede humana como um continuum em permanente mudança e conservação, de forma simultânea e contraditória. O que o leva a demonstrar o social como um combinado de interdependências entre indivíduos em desenvolvimentos indeterminados e composto por jogos e alianças entre seus membros. Demonstra, também, que esses movimentos interacionais em redes humanas de ação nunca satisfazem a um projeto individual ou coletivo determinado, mas são sempre resultado do jogo e da sua composição singular de momentos específicos onde as alianças se formaram e do frágil conteúdo do conjunto de projetos díspares que a informam e que a satisfazem em uma contraposição com outras alianças e conformações - também singulares ou dispostas - contidas no jogo conformado pela balança eu-nós configurada em um tempo-espaço específico.

Dessa forma, o conceito de habitus pode ser entendido como a incorporação nos indivíduos de um ethos sociocultural no interior de uma sociabilidade dada, neles sedimentados como uma espécie de figuração constituída pela tradição, costumes e mores. Isto é, pelas maneiras, estilos e modos, moralidade, formas de agir e de conduta, e pelas construções imaginárias e formas dos eus e dos nós verem a si próprios, aos outros e ao mundo (ELIAS, 1997, p. 30-31). 
Em Elias, assim, diferente de Bourdieu, o conceito de habitus pode mudar com o tempo, porque, para a análise eliasiana, as experiências de um indivíduo no interior de uma configuração ou sociedade, ou de uma nação, e seus agrupamentos estão em movimento contínuo, mesmo que com mais lentidão em um momento e mais aceleração em outros, e, ao mesmo tempo, nesse processo vão se acumulando os novos aos habitus mais antigos, transfigurando-os, reformando-os ou sendo a eles incorporados, sempre com uma boa dose de tensão.

Elias enfatiza nesse movimento as tensões entre indivíduos e sociedade e novas conformações como fundamento, tanto dos processos sociais quanto das mudanças nos códigos de conduta e figurações emocionais dos indivíduos e das redes por eles dispostas. Embora, de acordo com a sua análise, um substrato dessas tensões e conformações possa preexistir por uma longa duração, no imaginário e nas pulsões sociais e pessoais dos indivíduos que coabitam um mesmo espaço interacional em termos de interdependência e modos de vida comum: em forma, enfim, de um povo. $\mathrm{O}$ que deixa marcas peculiares no registro cultural, social e emocional de uma sociabilidade dada, tanto em nível individual quanto coletivo.

O conceito de habitus eliasiano, deste modo, implica sempre uma noção de equilíbrio na balança eu-nós no interior das tensões emocionais e configuracionais das redes de interdependência e de novas conformações que se dão nos processos de continuidade, conformidade e mudança ${ }^{11}$.

\section{Interdependência entre pessoas}

A Sociologia Figuracional eliasiana, assim, segundo o próprio Elias (1994, p. 150-151), parte da definição da sociedade, como já dito anteriormente, como uma rede humana, ou melhor, como "uma interdependência das pessoas", que, para ele, tem o sentido de ver o social como uma espécie de "estruturas sociais entrelaçadas". Desta maneira, o conceito de Figuração ou de Configuração pode ser entendido como o padrão mutável

11 Ver, por exemplo, as páginas 35 a 51 de Os alemães (ELIAS, 1997), onde trata de forma acurada da questão. 
criado pelo conjunto dos participantes ${ }^{12}$, isto é, pela totalidade das ações individuais nas relações que sustentam uns indivíduos aos outros em uma figuração, em uma sociedade ou em uma Rede Humana.

Esta figuração, de acordo com o raciocínio eliasiano, forma uma espécie de entrelaçado flexível de tensões. Formulação, ao que parece, que leva ao entendimento de que a interdependência dos participantes na rede humana configuracional só pode ser pensada como uma interdependência de aliados ou de adversários. É nessa direção e sentido que Elias define o conceito de forças sociais, importante em sua conformação teórica. Para Elias (1980), desse modo, a noção de forças sociais pode ser definida como a energia exercida pelas pessoas sobre as outras pessoas e sobre elas próprias.

Nesse movimento próprio de reflexão, compreende o conceito de totalidade social como uma configuração de seres humanos interdependentes (ELIAS, 1980). Compreensão que remete o conceito de totalidade social à noção de Equilíbrio, este pensado, por sua vez, através da figura de uma balança eu-nós. É através do conceito de equilíbrio, pensado através de uma balança eu-nós e pressuposto a partir de uma noção de totalidade social, vista como uma interdependência tensional entre seres humanos no encontro dos outros e de si próprios, que Elias chega ao conceito de Ordem Social.

O conceito de ordem social em Elias parte do mesmo pressuposto e se encontra no interior do mesmo sentido do que ele intitula Ordem Natural. Assim, de acordo com sua análise (ELIAS, 1980), a decadência e a destruição têm o seu lugar, lado a lado, com o crescimento. E a morte e a desintegração habitam, lado a lado, com o nascimento e a integração. Dessa forma, nesta mesma lógica reflexiva, o conceito de função, em Elias, deve ser entendido como um conceito que pressupõe relação: só se pode falar em funções sociais quando se está referindo a interdependências, que constrangem as pessoas dentro de uma maior ou de uma menor amplitude (ELIAS, 1980). E, nessa mesma direção reflexiva, compreende o cotidiano e sua rotinização como o campo fundamental de interesse das ciências sociais e de sua busca de compreensão do social (ELIAS, 1980, p. 112).

Em um primeiro esforço de síntese do até agora falado, se pode dizer que, para Elias (1994), os indivíduos em sociedade vivem uma existência não finalista, por onde se misturam imagens variáveis de seus objetivos,

12 Como metáfora para a ilustração, Elias utiliza a imagem dos jogos coletivos, como o futebol, entre outros. 
em uma espécie de "ordem invisível da vida em comum". Ordem invisível esta que não pode ser diretamente percebida em forma de funções e de comportamentos possíveis.

A todo ou em cada momento os indivíduos se encontram em movimento, criando um "tecido de relações móveis" (ELIAS, 1994, p. 28) e afirmando o social (nós) e a individualidade de cada ser humano em sociedade. Por outro lado, mas seguindo a mesma lógica reflexiva, todo o processo de individualização depende da rede de relações sociais que conformam a estrutura de uma dada sociedade.

A individualidade, deste modo, é específica de cada sociedade e a cognoscividade dos indivíduos sociais produz uma autoimagem individual que constituirá a roupagem externa de suas relações com os outros indivíduos. Esta autoimagem, por sua vez, constitui a expressão singular de uma também singular conformação histórica dos indivíduos em suas relações (ELIAS, 1994, p. 32).

Falando agora em termos da sociologia processual eliasiana, se pode perguntar quais seriam os princípios básicos da sua Sociologia. Utilizando aqui um artigo de Elias intitulado "Zeitschrift für Gundlegung einer Theorie sozialer Prozesse" ("Para uma teoria dos processos sociais"), publicado no Zeitschrift für Soziologie (Jornal de Sociologia) (ELIAS, 1977) e com versão em inglês no British Journal of Sociology, com o título "Towards a theory of social processes" (ELIAS, 1997a), é possível responder a esta questão levantando quatro pontos principais. O primeiro deles informa que para Elias as ciências sociais e a sociologia, em particular, trabalham com os indivíduos no plural, o que ele identifica conceitualmente como figurações. O segundo ponto informa que estas figurações, ou melhor, esses indivíduos no plural, agem de forma interdependente e se encontram em constante fluxo, isto é, em movimento continuado.

Seguindo a lógica do raciocínio, o terceiro ponto fala dos processos de desenvolvimento de longo prazo, que são, em larga medida, desenvolvimentos não planejados e não previsíveis. Para fechar a reflexão, o quarto ponto indica que o desenvolvimento dos saberes social e individual só pode se dar no interior das figurações, isto é, se processa internamente, por meio das relações travadas por esses indivíduos no plural e as redes que formam e conformam continuamente as interações, conformando uma cultura e uma economia emocionais como produto das experiências e da vivência desses indivíduos em redes. 
Assim, de acordo com Elias, o termo figuração pode ser definido como redes formadas por seres humanos interdependentes, com mudanças assimétricas na balança do poder. Esse modo conceitual dá ênfase ao caráter processual e dinâmico das redes criadas pelos indivíduos e traz em si o efeito demonstrativo de informar que é incorreto explicar eventos sociais em função das ações humanas intencionais. Para Elias, deste modo, os processos são engendrados pelo entrelaçar de ações intencionais e planos de muitos indivíduos, embora nenhum deles os tenha planejado ou desejado individualmente.

Segundo Elias (1980, p. 50), no livro Introdução à Sociologia, a interpenetração de indivíduos interdependentes forma um nível de integração em que as formas de organização, as formas de estruturação social e os processos não podem ser deduzidos das características biológicas ou psicológicas que constituem os indivíduos. De acordo com a teoria eliasiana, assim, os processos sociais e culturais estão estruturados ao longo do processo civilizatório de uma rede humana singular. Para explicar melhor esse pensamento, Elias (1987), em um longo artigo publicado na revista Theory, Culture and Society, intitulado "The retreat of sociologists into the present" ("O refúgio dos sociólogos no presente"), informa ao leitor as quatro funções elementares das redes humanas ou sociedades ${ }^{13}$ : a primeira função, para ele, tem base econômica e se encontra associada à sobrevivência dos indivíduos; a segunda é associada ao controle da violência, interna e externa; a terceira função, por sua vez, estaria ligada ao processo de obtenção do saber; e a quarta função, por fim, seria a função de autocontrole.

De posse dessas quatro funções, Elias (1980, p. 52) afirma que a individualidade só pode ser vista através da expressão da maneira particular, bem como do grau em que a forma do comando psíquico de um indivíduo se distingue dos demais indivíduos. O que o leva a afirmar que a sociedade não é apenas um fator de uniformização, mas, também, de individualização (ELIAS, 1980, p. 103).

O que nos faz retomar, aqui, mais uma vez, a importância da noção de habitus na obra eliasiana. A noção de habitus, em Elias (1990; 1993), no seu livro O processo civilizador, descreve a maneira como são individualmente incorporadas as modalidades de percepção e de ação coletivamente

13 Convém lembrar, aqui, que o conceito de função em Elias está vinculado ao de relações, como já se indicou anteriormente neste artigo. 
desenvolvidas no sistema de interações. Desse modo, o conceito eliasiano de habitus fornece um meio concreto de contornar a dicotomização indivíduo e sociedade, ao mostrar que as emoções e as disposições vividas no plano individual se devem a processos coletivos de incorporação, amplamente inconscientes.

Deste modo, é possível perceber que a noção de habitus em Elias engloba processos que vão dos comportamentos mais individualizados aos mais compartilhados, coletivos. O conceito de habitus eliasiano, assim, conduz os indivíduos nele envolvidos a serem ao mesmo tempo depositários e atores de uma identidade coletiva, ou melhor, como um ethos ou como uma identidade nacional, como ele trabalha, por exemplo, em Os alemães (1997).

O conceito eliasiano de habitus, assim, aponta para a concretização das relações praticadas entre planos muito diferentes e heterogêneos da experiência; relações que vão, de acordo com a análise desenvolvida em $O s$ alemães, desde a competência para a interação subscrita no espaço social até a performance produzida pelos indivíduos em situação.

\section{Notas finais}

Em resumo, no conjunto de sua obra Elias argumenta que o processo civilizador, no ocidente, se constituiu e emergiu assentado em uma nova sensibilidade, cuja característica principal pode ser assentida no processo de internalização da vergonha, visto como um dos conceitos-chave para a análise das emoções e das relações entre indivíduos e sociedade. Processo este que tornou possível um crescente e expandido controle dos impulsos e conduziu à racionalização da economia psíquica mediante a diferenciação interior da vida interna dos indivíduos em redes inter-relacionais. A obra eliasiana deste modo elabora - como vimos no decorrer deste ensaio - uma apreciação profunda sobre um amplo espectro de questões e temáticas, abrangendo, entrecruzando e, por que não, transcendendo e ultrapassando fronteiras disciplinares. Sua obra navega por campos disciplinares e teórico-metodológicos da história, da sociologia, da psicologia, da filosofia, da antropologia, da psicanálise e de outras áreas afins, e abre caminho para a compreensão da categoria emoções como uma categoria central para a 
análise de um social e de um cultural dado (KOURY, 2009). Esta elaboração permitiu a construção de um modelo lógico e coerente de apreensão da relação sempre tensa e ao mesmo tempo interdependente entre indivíduos e sociedade a partir do estudo do cotidiano de suas redes interacionais.

Cabe afirmar, por fim, que, de acordo com Elias, é preciso direcionar as ciências sociais e a sociologia, em particular, para o estudo dos processos, das mudanças e das relações. Isto é, para o estudo e pesquisa das práticas cotidianas e dos sistemas emocionais em rede e da dinâmica das posições, como, por exemplo, o processo de estigmatização em uma rede humana singular, ou em um coletivo específico, como o trabalhado por ele no livro Os estabelecidos e os outsiders (ELIAS, 2000), ao invés de um direcionamento das investigações para uma ontologia dos seres, entendida no contexto eliasiano como o estudo das categorias sociais e das propriedades de classe, entre outros aspectos.

Essa nota sobre a necessidade de mudança do olhar compreensivo na pesquisa das ciências sociais como um todo e na sociologia, de modo particular, traz um alerta sobre a obrigatoriedade destes campos científicos de romper com a dura fachada dos conceitos reificantes que reforçam a impressão de que a sociedade é composta de formações apenas situadas fora do "eu" singular, do indivíduo, deixando de lado a vida pulsante e tensional das interdependências entre os seres humanos que possibilitam configurações sociais e culturais específicas, em contínuo movimento, isto é, sempre em possibilidade tensional de mudança e mutação, e que são o fundamento da teoria social eliasiana e ponto de partida de uma sociologia das emoções.

\section{Referências}

BOURDIEU, Pierre. Travail et travailleurs en Algérie. Paris-La Haye: Mouton, 1963. Zouk, 2011.

A distinção: crítica social do julgamento. São Paulo: EDUSP; Porto Alegre:

DUNNING, Eric; MENNELL, Sthephen. Prefácio à edição inglesa. In: ELIAS, Norbert. Os alemães: a luta pelo poder e a evolução do habitus nos séculos XIX e XX. Rio de Janeiro: Zahar, 1997. p. 7-14. 
ELIAS, Norbert. Zur Grundlegung einer Theorie sozialer Prozesse. Zeitschrift für Soziologie [ZfS], v. 6, n. 2, p. 127-149, 1977.

. Introdução à sociologia. Lisboa: Edições 70, 1980.

. The retreat of sociologists into the present. Theory, Culture and Society, v. 4, n. 2, p. 223-247, 1987.

Zahar, 1990 .

. O processo civilizador: uma história dos costumes. v. 1. Rio de Janeiro: . O processo civilizador: formação do Estado e civilização. v. 2. Rio de Janeiro: Zahar, 1993.

. A sociedade dos indivíduos. Rio de Janeiro: Jorge Zahar, 1994.

. Os alemães: a luta pelo poder e a evolução do habitus nos séculos XIX e XX. Rio de Janeiro: Jorge Zahar, 1997.

. Towards a Theory of Social Processes: A Translation. Tradução e comentários de R. van Krieken, E Dunning The British Journal of Sociology, v. 48, n. 3, p. 355-383, 1997a.

. Sobre o tempo. Rio de Janeiro: Jorge Zahar, 1998.

. Os estabelecidos e os outsiders. Sociologia das relações de poder a partir de uma pequena comunidade. Rio de Janeiro: Jorge Zahar, 2000.

. A sociedade de corte: investigação sobre a sociologia da realeza e da aristocracia de corte. Rio de Janeiro: Zahar, 2001.

HEINICH, Nathalie. A sociologia de Norbert Elias. Bauru, SP: EDUSC, 2001.

KILMINSTER, Richard. Editor's introduction. In: ELIAS, Norbert. The Symbol Theory. London: Sage, 1995. p. VII-XXV.

KOURY, Mauro Guilherme Pinheiro. A formação do homem melancólico: luto e sociedade no Brasil. Cadernos de Ciências Sociais, João Pessoa: PPGS-UFPB, n. 38, 1996. Vozes, 2003.

. Sociologia da emoção. O Brasil urbano sob a ótica do luto. Petrópolis: . Emoções, sociedade e cultura: a categoria de análise emoções como objeto de investigação sociológica. Curitiba: Ed. CRV, 2009.

MENNELL, Stephen. Norbert Elias: an introduction. Dublin: University College Dublin Press, 1998. 
SCHEFF, Thomas J. Microsociology: discourse, emotion and social structure. Chicago: University of Chicago Press, 1990.

. Três pioneiros na sociologia das emoções. Tradução de Mauro Guilherme Pinheiro Koury. Política e Trabalho, n. 17, p. 115-127, 2001.

. Unpacking the civilizing process: shame and integration in Elias's work. RBSE - Revista Brasileira de Sociologia da Emoção, v. 1, n. 1, abril de 2002. 2003. . Shame in Self and Society. Symbolic Interaction, v. 26, n. 2, p. 239-262,

Recebido em outubro de 2013. Aprovado em novembro de 2013. 